\title{
Rays, intrusive growth, and storied cambium in the inflorescence stems of Arabidopsis thaliana (L.) Heynh
}

\author{
Ewa Mazur • Ewa Urszula Kurczynska
}

Received: 16 December 2010 / Accepted: 31 January 2011 /Published online: 12 February 2011

(C) The Author(s) 2011. This article is published with open access at Springerlink.com

\begin{abstract}
Arabidopsis thaliana is a model plant used in analysis of different aspects of plant growth and development. Under suitable conditions, secondary growth takes place in the hypocotyl of Arabidopsis plants, a finding which helps in understanding many aspects of xylogenesis. However, not all developmental processes of secondary tissue can be studied here, as no secondary rays and intrusive growth have been detected in hypocotyl. However, results presented here concerning the secondary growth in inflorescence stems of Arabidopsis shows that both secondary rays and intrusive growth of cambial cells can be detected, and that, in the interfascicular regions, a storied cambium can be developed.
\end{abstract}

Keywords Arabidopsis · Cambium · Inflorescence stems · Intrusive growth $\cdot$ Rays $\cdot$ Secondary growth $\cdot$ Storied cambium

\section{Introduction}

Arabidopsis thaliana is a model plant widely used to analyze mechanisms of different developmental processes both in vivo and in vitro (Kurczynska et al. 2007; Koornneef and Meinke 2010; Nieminen et al. 2004; Vieten et al. 2005). It has been shown that this perennial plant can undergo secondary growth under suitable conditions and it

Handling Editor: Peter Nick

E. Mazur $(\bowtie) \cdot$ E. U. Kurczynska

Laboratory of Cell Biology, Faculty of Biology

and Environmental Protection, University of Silesia,

ul. Jagiellonska 28,

40-032 Katowice, Poland

e-mail: ewa.mazur@us.edu.pl can therefore be used as a model plant for analysis of the molecular and genetic mechanisms leading to secondary wood formation, xylogenesis, cambial cell differentiation, divisions, and maturation (Chaffey 2002; Chaffey et al. 2002; Ko and Han 2004; Ko et al. 2004; Zhao et al. 2000).

Secondary growth in Arabidopsis was described in detail in the case of the hypocotyl (Chaffey et al. 2002). In this organ, secondary growth and cambial activity resembles, in most features, the anatomy and behavior of secondary growth in angiosperm trees (Chaffey 2002; Chaffey et al. 2002). The only difference between secondary growth in Arabidopsis hypocotyl and trees is that the former lacks both secondary rays and intrusive cambial cell growth. These two features are important for a full understanding of the mechanisms controlling cambium and differentiation of cambial cells derivatives (Altamura et al. 2001; Barlow 2005; Barlow and Lück 2006; Barlow et al. 2010; Ko and Han 2004; Ko et al. 2004; Lev-Yadun 1997; Lev-Yadun and Flaishman 2001).

Analysis of secondary growth and development in inflorescence stems of Arabidopsis under artificial weight treatment revealed that, in these stems, not only rays and intrusive growth can be found, but also development of storied cambium takes place. The aim of the present study is to describe cambial features which accompany secondary growth in Arabidopsis inflorescence stems.

\section{Materials and methods}

Plant material and growth conditions

A. thaliana (L.) Heynh. (Columbia ecotype) seeds were germinated in a soil-vermiculite $(1: 1 v / v)$ mixture for 7 days in a growth chamber at $20^{\circ} \mathrm{C}$ with a $16 / 8$-h L/D photoperiod. To induce inflorescence stem growth, individ- 
ual seedlings with a second pair of leaves were selected. They were then grown individually in 6-cm-diameter pots in a growth chamber at $20^{\circ} \mathrm{C}$ having an $8 / 16-\mathrm{h} \mathrm{L} / \mathrm{D}$ photoperiod for 8 weeks.
Design of the experiment

To obtain secondary growth in the inflorescence stems, the method described by Ko et al. (2004) was used with some
Fig. 1 a-i Structure and activity of the cambium in inflorescence stems of $A$. thaliana with secondary growth. a The cambial zone in the fascicular and interfascicular regions of the basal part of the stem (arrow). b Anticlinal divisions of fusiform initials in the cambial zone (arrow) and two rays extending from secondary phloem to secondary xylem (circles). c, d The uniseriate rays consist of a few ray cells (double arrows). e An intrusively growing lower end of a fusiform cell (arrow) at the radial edge of a neighboring fusiform cell. f Intrusive growth of the lower (arrows in frames) and upper (open arrows in frames) fusiform cell-ends in the cambial zone. g Secondary growth characterized by storied cambium in the interfascicular region of the basal part of an inflorescence stem. $\mathbf{h}$ Stories of fusiform cells (triple arrows) created from parenchyma cells after their radial longitudinal divisions (arrow). i Non-storied, fascicular cambium developed within a vascular bundle. Fusiform cells are arranged on different levels and the growth activity of their ends can be observed (double arrows). In the interfascicular region, both vessels and fibers are present. Abbreviations: $f s c$ fascicular region, ifsc interfascicular region, $e$ epidermis, $c x$ cortex, $n c$ non-storied cambium, $s c$ storied cambium, $V$ vessels, $F$ fibers. a, b cross sections, $\mathbf{c}-\mathbf{i}$ longitudinal sections. Scale bars $100 \mu \mathrm{m}$ (a), $50 \mu \mathrm{m}$ (g), $25 \mu \mathrm{m}$ (b), $10 \mu \mathrm{m}(\mathbf{c}-\mathbf{f}), 5 \mu \mathrm{m}(\mathbf{h}, \mathbf{i})$
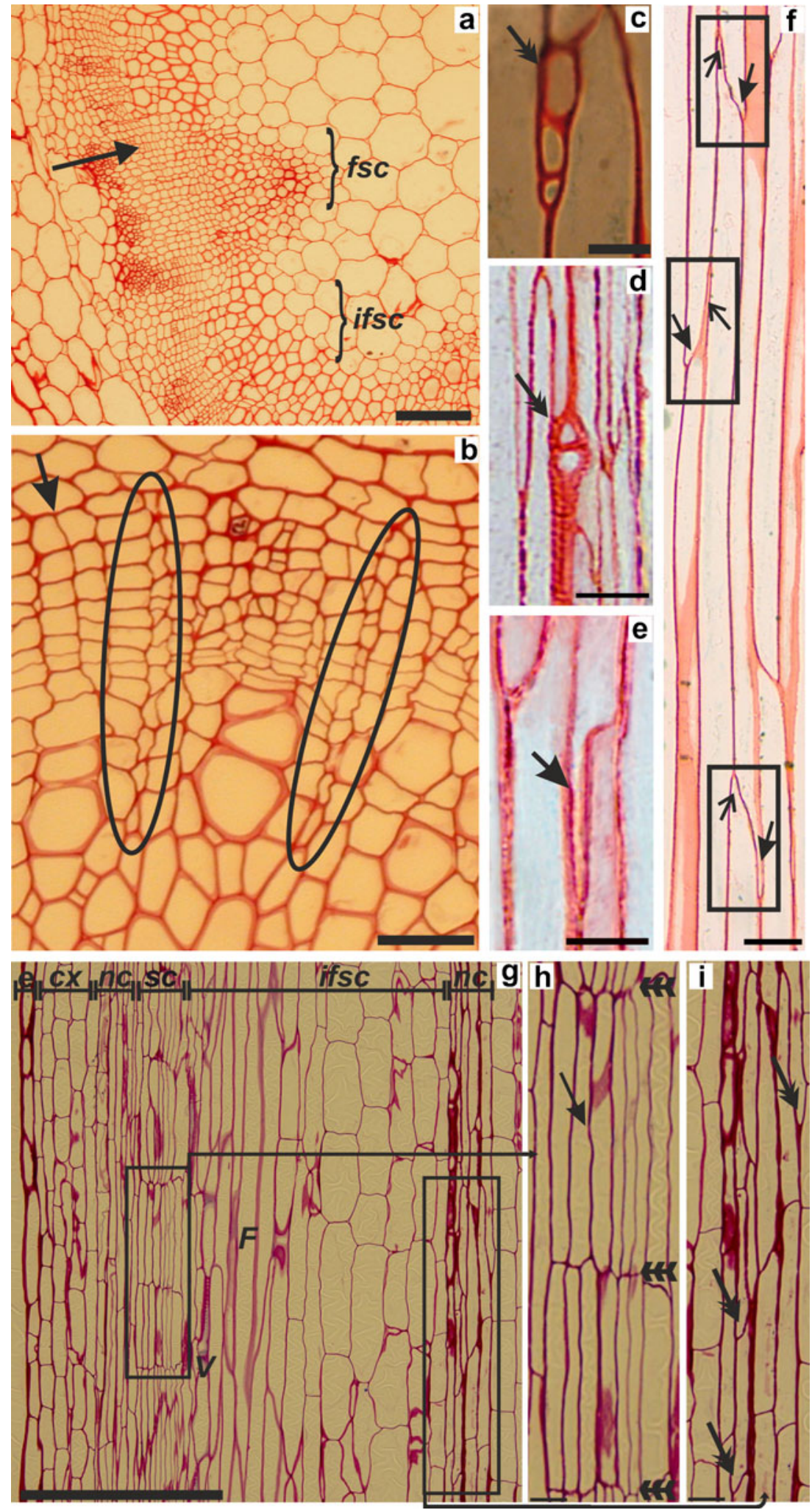
modifications. In this method, development of secondary vascular tissue is much faster (by several days) in comparison to the earlier method (which takes a few months) described by Chaffey et al. (2002). Plants were decapitated by removing the terminal $1-2 \mathrm{~cm}$ of shoot apex and stem. Inflorescence stems were then covered by a rubber tube and, at the top of the tube, a 2.5 -g weight was placed. In such conditions, plants were grown for 6 days (anatomical analysis shown that after this time interfascicular cambium was present and actively producing the secondary xylem) at $20^{\circ} \mathrm{C}$ and in an 8/16-h L/D photoperiod. The experiments were performed on 26 inflorescence stems and were repeated twice.

\section{Histological analysis}

For histological analysis, pieces (15 $\mathrm{mm}$ in length) of tissues from the basal part of inflorescence stems were taken, fixed overnight at $4 \pm 1{ }^{\circ} \mathrm{C}$ with $2 \%$ glutaraldehyde in 1/15 M phosphate buffer ( $\mathrm{pH} 7.2$ ), dehydrated with an ethanol series, embedded in Epon resin, and, after polymerization, cut into a series of semi-thin sections $(2-\mu \mathrm{m}$ thick) on the ultramicrotome (Leica EM UC6) with the diamond knife. Sections were attached to microscopic slides with Haupt's adhesive (procedure described by O'Brien and McCully 1981), stained with periodic acid-Schiff reaction plus toluidine blue, and mounted under a coverslip in Euparal (Carl Roth, Karlsruhe, Germany). Sections were observed by transmitted light with an Olympus BX41 photomicroscope equipped with a CCD photo camera.

\section{Results and discussion}

Secondary growth in inflorescence stems was visible after several days from the induction of this process according to the earlier-described method (Ko et al. 2004). A continuous layer of cambium and its derivatives (Fig. 1a) was detected in the basal part of these stems. Detailed analysis of a series of longitudinal and cross sections through the stems showed presence of secondary rays continuous from phloem to xylem through the cambial zone (Fig. 1b). Rays were always uniseriate, and were two to seven cells in height (Fig. 1c, d). This means that cambium consists of two distinct initials, fusiform and ray, which are responsible for nutrients transport across secondary vascular tissues $(\mathrm{Du}$ and Groover 2010). All features of the secondary rays in Arabidopsis inflorescence stems are similar to the rays originating from the vascular cambium in the woody plants (Barlow 2005; Evert 2006). So far, only the primary parenchymatous rays have been described in Arabidopsis hypocotyls (Busse and Evert 1999), but secondary rays have not previously been found (Chaffey et al. 2002). These observations have led to the opinion that Arabidopsis does not mimic tree systems in all developmental processes. The results presented here may change this opinion.

The findings presented in this paper are the first to describe the intrusive growth of cambial cells, which takes place during the secondary growth in Arabidopsis inflorescence stems (Fig. 1e, f). Intrusive growth is a process typical for angiosperms trees and is responsible for maintaining the length of cambial derivatives. It is due to oblique anticlinal divisions of cambial cells which thereby shorten the length of the cambial initial cells (Larson 1994; Siedlecka et al. 2008). This mechanism for maintaining the length of the cambial cells relies on their intrusive growth (Hejnowicz 1964; Larson 1994).

The third feature of cambial development discovered in inflorescence stems of Arabidopsis is the presence of storied cambium in the part which is called the interfascicular region. Storied cambium was present only in this region, and was never observed in fascicular zone (Fig. 1g, $\mathrm{h}, \mathrm{i})$. Storied cambium is phylogenetically advanced in comparison to non-storied cambium (Barlow 2005; Romberger et al. 1993; Myśkow and Zagórska-Marek 2008). The fusiform cambial initials in storied cambium are arranged circumferentially in defined rows in which the cells are of similar length. In trees, storied cambium develops gradually from non-storied cambium (Larson 1994; Myśkow and Zagórska-Marek 2008). The presence of storied cambium in Arabidopsis should therefore be helpful in analysis of mechanisms operating during the secondary growth. Moreover, it suggests that cells in interfascicular zones, which have changed their developmental fate from parenchymatous to meristematic, behave in different way to cells in the fascicular cambial zone.

The features of cambium described in the present paper should help in the understanding of many developmental processes concerning the secondary growth of plants, particularly when different transgenic lines and mutants of Arabidopsis are employed.

Acknowledgment We thank Prof. Peter Barlow for his help in preparation of the English version of the manuscript.

Conflicts of interest statement The authors declare that they have no conflict of interest.

Open Access This article is distributed under the terms of the Creative Commons Attribution Noncommercial License which permits any noncommercial use, distribution, and reproduction in any medium, provided the original author(s) and source are credited.

\section{References}

Altamura MM, Possenti M, Matteucci A, Baima S, Ruberti I, Morelli G (2001) Development of the vascular system in the inflorescence stem of Arabidopsis. New Phytol 151:381-389 
Barlow PW (2005) From cambium to early cell differentiation within the secondary vascular system. In: Holbrook NM, Zwieniecki MA (eds) Vascular transport in plants. Elsevier/Academic, Amsterdam/New York, pp 279-306

Barlow PW, Lück J (2006) Patterned cell development in the secondary phloem of dicotyledonous trees: a review and a hypothesis. J Plant Res 119:271-291

Barlow PW, Mikulecky S, Střeštik J (2010) Tree-stem diameter fluctuates with the lunar tides and perhaps with geomagnetic activity. Protoplasma 247:25-43

Busse JS, Evert RF (1999) Pattern of differentiation of the first vascular elements in the embryo and seedling of Arabidopsis thaliana. Int J Plant Sci 160:1-13

Chaffey N (2002) Why is there so little research into the cell biology of the secondary vascular system of trees? New Phytol 153:213223

Chaffey N, Cholewa E, Regan S, Sundberg B (2002) Secondary xylem development in Arabidopsis: a model for wood formation. Physiol Plant 114:594-600

Du J, Groover A (2010) Transcriptional regulation of secondary growth and wood formation. J Integr Plant Biol 52(1):17-27

Evert RF (2006) Esau's plant anatomy: meristems, cells, and tissues of the structure, function, and development, 3rd edn. Wiley, New Jersey

Hejnowicz Z (1964) Anticlinal divisions, intrusive growth and loss of fusiform initials in nonstoried cambium. Can J Bot 42:1685-1691

Ko JH, Han KH (2004) Arabidopsis whole-transcriptome profiling defines the features of coordinated regulations that occur during secondary growth. Plant Mol Biol 55:433-453

Ko JH, Han KH, Park S, Yang J (2004) Plant body weight-induced secondary growth in Arabidopsis and its transcription phenotype revealed by whole-transcriptome profiling. Plant Physiol 135:1069-1083

Koornneef M, Meinke D (2010) The development of Arabidopsis as a model plant. Plant J 61:909-921
Kurczynska EU, Gaj MD, Ujczak A, Mazur E (2007) Histological analysis of direct somatic embryogenesis in Arabidopsis thaliana (L.) Heynh. Planta 226:619-626

Larson PR (1994) The vascular cambium. Development and structure. Springer, Berlin

Lev-Yadun S (1997) Fibres and fibre-sclereids in wild-type Arabidopsis thaliana. Ann Bot 80:125-129

Lev-Yadun S, Flaishman MA (2001) The effect of submergence on ontogeny of cambium and secondary xylem and on fiber lignification in inflorescence stems of Arabidopsis. IAWA J 22:159-169

Myśkow E, Zagórska-Marek B (2008) Vertical migration of rays leads to the development of double-storied phenotype in the cambium of Aesculus turbinata. Can J Bot 86:36-44

Nieminen KM, Kauppinen L, Helariutta Y (2004) A weed for wood? Arabidopsis as a genetic model for xylem development. Plant Physiol 135:653-659

O'Brien TP, McCully ME (1981) The study of plant structure. Principles and selected methods. Termarcarphi Pty Ltd, Melbourne

Romberger JA, Hejnowicz Z, Hill JF (1993) Plant structure: function and development. A treatise on anatomy and vegetative development, with special reference to woody plants. Springer, Berlin, pp 353-385

Siedlecka A, Wiklund S, Peronne MA, Micheli F, Lesniewska J, Sethson I, Edlund U, Richard L, Sundberg B, Mellerowicz EJ (2008) Pectin methyl esterase inhibits intrusive and symplastic cell growth in developing wood cells of Populus. Plant Physiol 146:554-565

Vieten A, Vanneste S, Wiśniewska J, Benková E, Benjamins R, Beeckman T, Luschnig C, Friml J (2005) Functional redundancy of PIN proteins is accompanied by auxin-dependent crossregulation of PIN expression. Development 132:4521-4531

Zhao C, Johnson BJ, Kositsup B, Beers EP (2000) Exploiting secondary growth in Arabidopsis. Construction of xylem and bark cDNA libraries and cloning of three xylem endopeptidases. Plant Physiol 123:1185-1196 